\title{
ASPECTOS AMBIENTAIS NA RESPOSTA FISIOLÓGICA DE VACAS GIROLANDO NA PRÉ-ORDENHA
}

\author{
BARBOSA, Mônica Machado ${ }^{1}$ \\ PEREIRA, Ariany Dos Reis ${ }^{1}$ \\ MELLO, Silvio De Paula²
}

Recebido em: 2021.03.10 Aprovado em: 2021.05.26 ISSUE DOI: $10.3738 / 21751463.3902$

RESUMO: O objetivo do experimento foi avaliar os aspectos ambientais e fisiológicos de 20 vacas da raça Girolando na pré-ordenha, submetidas ao ambiente sombreado e ao sol, no período de dezembro de 2018 a fevereiro de 2019. Foi realizado no setor da Bovinocultura Leiteira da Faculdade Dr. Francisco Maeda - FAFRAM da Fundação Educacional de Ituverava-SP, localizada no Sítio das Acácias. Foram coletadas as mensurações ambientais (temperatura ambiente, umidade relativa do ar, globo negro, índice de temperatura do globo e umidade), mensurações fisiológicas (frequências respiratórias e temperatura do pelame). As coletas foram feitas, duas vezes por semana em dois horários $(7 \mathrm{~h} 30 \mathrm{~m})$ da manhã e as (14h) da tarde, antes de cada ordenha. Os dados foram submetidos a análise de variância e as médias comparadas pelo teste de Tukey. As variâncias apresentaram valores médios na préordenha sem sombreamento, respectivamente para temperatura ambiente $38,16^{\circ} \mathrm{C}$, umidade relativa $40,82 \%$, temperatura de globo negro $38,50^{\circ} \mathrm{C}$, índice de temperatura de globo e umidade 87,60 , frequência respiratória 44,17 (mov.,- $\min ^{-1)}$; e temperatura do pelame $37,74^{\circ} \mathrm{C}$. Conclui-se que vacas leiteiras da raça Girolando expostas ao sol na pré-ordenha avaliadas durante os meses de verão, estavam em estresse térmico. Durante a avaliação dos animais sob sombreamento, apresentaram valores intermediários na pré-ordenha utilizando sombrite, respectivamente para temperatura ambiente $35,64^{\circ} \mathrm{C}$, umidade relativa $37,67 \%$, temperatura de globo negro $35,62^{\circ} \mathrm{C}$, índice de temperatura de globo e umidade 83,94, frequência respiratória 42,08 (mov.,- $\mathrm{min}^{-1}$; e temperatura do pelame $34,75^{\circ} \mathrm{C}$. Certificando que diante das análises obtidas, a utilização de sombrite na pré-ordenha foi considerada pouco eficaz.

Palavras chave: Bem-Estar Animal. Estresse Térmico. Temperatura

\section{ASPECTS IN THE COW'S PHYSIOLOGICAL RESPONSE BEFORE MILKING}

SUMMARY:The objective of the experiment was to evaluate the environmental and physiological aspects of 20 Girolando cows in the waiting corral, submitted to the shaded environment and the sun, from December 2018 to February 2019. It was carried out in the dairy sector of Faculdade Dr. Francisco Maeda - FAFRAM of the Educational Foundation of Ituverava-SP, located at Sítio das Acácias. Environmental measurements (ambient temperature, relative air humidity, black globe, globe temperature index and humidity), physiological measurements (respiratory frequencies and hair temperature) were collected. Collections were made twice a week at two times $(7: 30 \mathrm{am})$ in the morning and at 2:00 pm in the afternoon, before each milking. The data were elaborated by analysis of variance and as means compared by the Tukey test. The variances mean values in the waiting corral without shading, respectively for ambient temperature $38.16^{\circ} \mathrm{C}$, relative humidity $40.82 \%$, black globe temperature $38.50^{\circ} \mathrm{C}$, black globe temperature index and humidity 87.60, respiratory rate 44, 17 (mov., - min-1); and fur temperature $37.74^{\circ} \mathrm{C}$. It is concluded that Girolando cows exposed to the sun in the pre-milk milking evaluated during the summer months, were under thermal stress. During the evaluation of animals under shading, intermediate values in the waiting pen with shade, respectively for room temperature $35.64^{\circ} \mathrm{C}$, relative humidity $37.67 \%$, black globe temperature $35.62^{\circ} \mathrm{C}$, globe temperature index and humidity 83,94 , respiratory rate 42.08 (mov., - min-1); and fur temperature $34.75^{\circ} \mathrm{C}$. Certifying that in the face of the analyzes, the use of a non-corral waiting hatch in pre-milking was considered little considered effective.

Keywords: Animal welfare. Thermal stress. Temperature.

\footnotetext{
${ }^{1}$ Médica Veterinária.

${ }^{2}$ Docente dos cursos de Agronomia e Medicina Veterinária Faculdade Dr. Francisco Maeda/Fundação Educacional de Ituverava
} 


\section{INTRODUÇÃO}

Durante o ano de 2020, o rebanho bovino no Brasil demostrou grande avanço, chegando a um total de 214,7 milhões de cabeças de gado, com a alta de 0,4\% divulgada pelo IBGE (BARROS, 2020).

No início do semestre o mercado do leite teve uma valorização de 42,5\%, na "Media Brasil". Desta forma, o ano de 2020 foi marcado pela elevação dos preços especialmente no mês de agosto, onde chegou ao recorde de $\mathrm{R} \$ 1,9426 /$ litros de leite na "Média Brasil" com alta de 39,7\% (CANAL RURAL, 2020).

Grande parte dos animais leiteiros que foram introduzidos no Brasil é de origem europeia, destacando-se a raça Girolando. A raça Girolando é resultado do cruzamento entre bovinos europeus (Bosass primigenius taurus) da raça holandesa com bovinos zebuínos da raça Gir (Bos primigenius indicus) (GIROLANDO, 2019).

As vacas de origem europeia são utilizadas exclusivamente para finalidade de produção de leite, contam com um metabolismo elevado com grande produção de calor endógeno (MARTELLO et al., 2004).

O clima do Brasil, é o principal fator que influencia no bem-estar animal e na produção de leite (PEREIRA, 2005), pois $2 / 3$ do território brasileiro ocupa a área tropical do planeta resultando em altas temperaturas, devido à alta radiação solar (MARIA et al., 2009).

As vacas leiteiras contam com uma zona de termoneutralidade (ZTN) tem como finalidade manter o equilíbrio da temperatura corporal do animal, sem que se faça esforço fisiológico. Desta forma, este equilíbrio é mantido pelo calor que é produzido pelo corpo e o calor que é ganho ou perdido para o ambiente (MARCELLINO et al., 2017).

Quando o animal sofre estresse por calor ele se alimenta com pouca frequência, pois tem necessidade de dissipar calor para o ambiente, assim a produção interna de calor se encontra baixa, já durante o estresse por frio o animal tende a se alimentar com maior frequência devido a necessidade de produzir calor interno (LALONI, 2011).

Para Baccari (1998), o estresse ocorre de forma externa ou interna gerando incomodo ao animal. Assim respostas fisiológicas, comportamentais e imunológicas são desencadeadas devido ao incomodo que o animal sofreu podendo se desenvolver de maneira aguda, crônica repetida e combinada.

Pesquisadores relatam que o momento de maior estresse sofrido por vacas lactantes em período de produção leiteira ocorre durante a pré-ordenha, localizada no curral de espera devido ao calor intenso. Desta forma, o mais indicado é que o animal permaneça o menor tempo possível na pré-ordenha quando o local não possui instalações cobertas (REHAGRO, 2018). 
A importância do uso de sombreamento é totalmente positiva quando é proporcionado sombreamento aos animais. O sombreamento age diretamente na radiação, que é responsável por causar estresse térmico aos animais, evitando que a radiação interfira em outros fatores como: temperatura e umidade do ar (FERREIRA, 2010).

O uso de sombreamento artificial utilizando sombrite tem sido o melhor método a se adotar, pois é um método prático e barato que proporciona grau variado de interceptação da radiação solar direta, que podem variar de $30 \%$ a $90 \%$ de interceptação solar. O material de preferência a se utilizar é o de polipropileno com $80 \%$ de grau de interceptação solar (CARVALHO, 2019), existem também outros tipos de grau de interceptação solar a se considerar que são eles 40\%, 50\%, 70\% (JULIVAN, 2018).

Segundo Carvalho (2019), existe várias características a serem consideradas para que possa ter bons resultados com o uso de sombreamento artificial através de sombrite e a principal refere-se a altura e o mês pois, quanto mais alto o pé direito do sombrite melhor será a passagem de ar pelo telhado, atuando na temperatura gerando pouco calor ao animal, o mês em que se utiliza o sombrite também é visto como importante, durante os meses de verão ocorre maior proporção de sombra sob a estrutura, pois o eixo maior do sombrite está voltado para o lesteoeste, já durante o período de umidade recomenda-se a utilização de norte-sul.

Desta forma, quando ocorre um simples fornecimento de sombra (artificial ou natural) gera bem-estar ao animal, faz com que durante os meses de verão o calor seja amenizado. Sendo assim, os animais aumentam a produção e ingestão de alimentos e água, pois estando em local sombreado não precisará parar o consumo para amenizar a produção de calor pelo organismo (SILVA, 2019).

Pereira (2005) indica técnicas programadas para casos em que os animais apresentem estados de estresse térmico referentes aos que foram citados acima nas seguintes condições:

Alerta: Neste estado os animais devem ser resfriado, através de ventilação e deve ser ofertado a eles água de boa qualidade e sombreamento. As respostas fisiológicas devem ser observadas também, através da ofegação do animal.

Perigo: Neste estado os animais devem ser resfriado com aspersores no processo de resfriamento do animal;

Emergencial: Neste estado deve-se evitar que, os animais sejam manejados e alimentados nas horas mais quentes do dia, deve ser fornecido sombreamento imediato, ventilação e aspersão aos animais;

O bem-estar animal possui participação forte de códigos morais, por isso o tratamento animal não é mais visto como algo que possa ser deixado para a livre escolha do pecuarista individual (BOND et al., 2012). 
O objetivo deste trabalho foi avaliar o bem-estar animal de vacas Girolando na préordenha, na ausência e presença de sombreamento proporcionado pelo sombrite, durante os meses de verão.

\section{MATERIAL E METODO}

Aprovado pela comissão de ética no uso de animais da Faculdade Dr. Francisco Maeda (CEUA/FAFRAM), protocolo 34/2018.

O experimento foi realizado no setor da Bovinocultura Leiteira da Faculdade Dr. Francisco Maeda - FAFRAM, da Fundação Educacional de Ituverava - SP Latitude: -20.345 Longitudes: -47.7861, localizada no Sítio das Acácias.

Foram avaliadas 20 vacas da raça Girolando em lactação, durante os meses de verão de dezembro de 2018 a fevereiro de 2019. Coletou-se informações na pré-ordenha sem sombrite, no período de 4 de dezembro de 2018 a 28 de dezembro de 2018.

Posteriormente permanecendo na pré-ordenha utilizando sombrite de material de polipropileno com $40 \%$ de interceptação solar de radiação, no período de 7 de janeiro a 22 de fevereiro de 2019, com o sombrite voltado para o Leste-Oeste.

Informações referentes a elementos climáticos (Temperatura de bulbo seco, globo negro e umidade relativa do ar), aspectos fisiológicos (temperatura do pelame e frequência respiratória) foram coletados na pré-ordenha no sol e sombra e por meio de dados ambientais foi calculado o índice de temperatura de globo e umidade (ITGU), através da fórmula:

\section{ITGU $=$ Tg $+0,36$ Tpo $+41,5$}

Em que:

$\mathrm{Tg}=$ Temperatura do termômetro de globo negro, ${ }^{\circ} \mathrm{C}$;

Tpo $=$ Temperatura do ponto de orvalho, ${ }^{\circ} \mathrm{C}$

As coletas foram realizadas duas vezes por semana em dois horários distintos na préordenha, pela manhã antes da ordenha $(07: 30 \mathrm{~h})$ e outro antes da ordenha do período da tarde (14:00h). A temperatura do pelame foi coletada através de um termômetro infravermelho mira laser a $5 \mathrm{~cm}$ de distância e os dados dos elementos climáticos foram coletados por um termohigrometro de bulbo seco e bulbo úmido e globo negro.

A frequência respiratória - FR (mov. $\left.\mathrm{min}^{-1}\right)$ foi obtida por intermédio da observação e contagem dos movimentos do flanco durante 15 segundos, realizada a correlação para um 
minuto. Os dados foram submetidos a análise de variáveis e as médias comparadas pelo teste de Tukey.

\section{RESULTADO E DISCUSSÃO}

As mensurações ambientais e médias de temperatura do ambiente (TA), umidade relativa do ar (UR), temperatura de globo negro (TGN) e índice de temperatura de globo e umidade (ITGU) de vacas da raça Girolando localizadas no curral de espera, expostas ao sol e com utilização de sombrite, estão descritas na Tabela 1.

Tabela 1 - As mensurações ambientais e médias de temperatura do ambiente (TA), umidade relativa do ar (UR), temperatura de globo negro (TGN) e índice de temperatura do globo e umidade (ITGU) de vacas da Girolando localizadas no curral de espera expostas ao sol e com a utilização de sombrite, Ituverava/SP, 2019.

\begin{tabular}{lcccc}
\hline \multicolumn{5}{c}{ MENSURAÇÕES AMBIENTAIS } \\
\hline & TA $\left({ }^{\mathbf{0}} \mathbf{C}\right)$ & UR $(\%)$ & TGN $\left({ }^{\circ} \mathbf{C}\right)$ & ITGU \\
Sol & 38,16 & 40,82 & 38,50 & 87,60 \\
Sombrite & 35,64 & 37,67 & 35,62 & 83,94 \\
Média geral & 37,01 & 39,38 & 37,18 & 85,94 \\
CV\% $^{*}$ & 4,40 & 2,36 & 3,45 & 4,20 \\
\hline Médias seguidas da mesma letra, na coluna, não diferem estatisticamente pelo teste de Tukey $(\mathrm{P}>0,05)$
\end{tabular}

Fonte: Elaborado pelos autores (2019).

Os aspectos observados na pré-ordenha com vacas da raça Girolando expostas ao sol e com utilização de sombrite, apresentaram variáveis acima do recomendado. O ideal é que novos trabalhos sejam realizados com sombrite que possua maior grau de interceptação solar.

Para Matarazzo (2004), cada animal possui uma necessidade e cada um necessita de um grau de temperatura diferente. A temperatura ideal para vacas leiteiras de origem europeia em lactação é de $4^{\circ} \mathrm{C}$ a $24^{\circ} \mathrm{C}$, podendo variar de acordo com suas características.

Para Pereira (2005), o estresse é considerado quando o valor de (TA) temperatura ambiente é maior que $30^{\circ} \mathrm{C}$. Com relação a esse valor, vacas da raça Girolando que foram avaliadas na pré-ordenha expostas ao sol, demostraram valores de (TA) de $38,16^{\circ} \mathrm{C}$ e com sombrite $35,64^{\circ} \mathrm{C}$, com média geral de $37,01^{\circ} \mathrm{C}$, indicando ocorrência de estresse térmico na préordenha, pois os valores obtidos ao sol e com sombrite se encontram acima do recomendado.

Para que a umidade relativa do ar possa ser considerada normal, é necessário que esteja entre $50 \%$ a $70 \%$. Porém, outros pesquisadores relataram que valores acima de 50\% são responsáveis pela baixa na produção, quando há aumento da umidade a transpiração animal é considerada baixa (NÃ̃̃S; SOUZA, 2003 apud MELLACE, 2009). Vacas da raça Girolando que foram avaliadas na pré-ordenha expostas ao sol demostraram valores de UR\% de 40,82\% e com 
sombrite apresentaram valores de UR\% 39,38\%, com média geral 39,28\%, indicando conforto térmico, pois os valores obtidos estão de acordo com o recomendado.

Segundo Baêta (1997), quando valores de ITGU são apresentados até 74 para vacas de origem europeia, é indicado conforto térmico, de 75 a 78 é considerado estado de alerta e acima de 84 é considerado estado totalmente prejudicial e emergencial. Com relação a isso, vacas da raça Girolando que foram avaliadas na pré-ordenha expostas ao sol demostraram valores de ITGU de 87,60 e com sombrite 83,84 com média geral de 85,94. Os valores obtidos das vacas da raça Girolando expostas ao sol indicam estresse térmico, enquanto com sombrite indica estado de alerta.

As mensurações ambientais e médias avaliadas a partir da frequência respiratória (FR) e temperatura do pelame (TP) de vacas Girolando no curral de espera, expostas ao sol e com utilização de sombrite, estão descritas na Tabela 2.

Tabela 2 - Médias da frequência respiratória (FR) e temperatura do pelame (TP), de vacas Girolando expostas ao sol e com utilização de sombreamento Ituverava/SP., 2019.

\begin{tabular}{lcc}
\hline \multicolumn{3}{c}{ MENSURAÇÕES FISIOLÓGICAS } \\
\hline & FR (mpm) & TP $\left({ }^{\circ} \mathbf{C}\right)$ \\
Sol & 44,17 & 37,74 \\
Sombrite & 42,08 & 34,75 \\
Média geral & 43,56 & 36,38 \\
CV\%* & 20,90 & 3,53 \\
\hline
\end{tabular}

Médias seguidas da mesma letra, na coluna, não diferem estatisticamente pelo teste de Tukey $(\mathrm{P}>0,05)$

Fonte: Elaborado pelos autores (2019).

Para Auad et al., (2010), a avaliação de parâmetros fisiológicos como a FR é considerada uma das melhores formas de se identificar o estresse calórico.

Quando animais são expostos ao sol, a frequência respiratória (FR) sofre alterações, pois o sol possui total influência sobre a frequência respiratória dos animais (DALCIN, 2013).

Halm et al., (1997), explica que para um animal ser considerado em estado de estresse térmico, a FR deve ser superior a 60 (mov., - min-1).

Segundo Hahn (1997 apud MATARAZZO, 2004) animais que apresentam FR de 120 (mov., - min-1) indicam carga excessiva de calor demonstrando sofrimento, já acima de 160 (mov., - min-1) é considerado estado emergencial e medidas devem ser tomadas. Devido a isso, os autores relatam que não existe uma afirmação que comprove a ideal faixa de frequência respiratória para bovinos leiteiros de origem europeia, mas relatam que, a ser considerado normal seja de 18 a 60 (mov., - min-1) e para ser considerado estresse térmico é necessário que apresente (FR) de 44 a 160 (mov., - min-1) (CONCEIÇÃO, 2008). Vacas da raça Girolando expostas ao sol 
apresentaram FR de 44,17 (mov., - min-1) e com sombrite apresentaram 42,08 (mov., - min-1), com média geral de 43,56. Indicando que animais avaliados ao sol e com sombrite estavam em estresse térmico, indicando estado de estresse moderado.

A perda de calor é vista como mecanismo e está relacionada com a temperatura do pelame (TP), pois é um dos mecanismos de perda de calor, sendo uma das principais respostas do animal ao estresse térmico. A temperatura para não ser considerado estresse térmico é entre $31,6^{\circ} \mathrm{C} \mathrm{e}$ $37,7^{\circ} \mathrm{C}$ (MARTELLO, 2004). Desta forma, vacas da raça Girolando que foram avaliadas expostas ao sol apresentaram valores de $\mathrm{TP}$ de $37,74^{\circ} \mathrm{C}$ e com sombrite $34,75^{\circ} \mathrm{C}$, com média geral de $36,38^{\circ} \mathrm{C}$, indicando que não houve estresse de vacas expostas ao sol e com sombrite, demostrando a presença de conforto, pois os valores obtidos são considerados ideias para vacas de origem europeia em lactação.

\section{CONCLUSÃO}

Nas condições em que foi realizado pode-se concluir que, os animais expostos ao sol e ao sombrite no curral de espera, avaliados durante o verão apresentaram variáveis acima do recomentado, indicando estresse térmico.

\section{REFERÊNCIAS}

AUAD, A. M. et al., Manual de bovinocultura de leite: Embrapa Gado de Leite. 3. ed. Brasília: Belo Horizonte, p. 608, 2010.

BACCARI, F.J.R. Adaptação de sistemas de manejo na produção de leite em clima quente. In: SIMPÓSIO BRASILEIRO DE AMBIÊNCIA NA PRODUÇẪO DE LEITE, 1, Anais... FEALQ Piracicaba. 1998.

BAÊTA, F.C.; SOUZA, C.F. Ambiência em edificações rurais: conforto animal. Viçosa: UFV, 246 p. 1997.

BOND, G.B. et al., Métodos de diagnóstico e pontos críticos de bem-estar de bovinos leiteiros. Ciência Rural, Santa Maria, v.42, n.7, p.1286-1293, jul., 2012.

BARROS, A. Rebanho bovino tem leve alta em 2019, após dois anos seguidos de quedas. Agência IBGE Noticia. Ribeirão Preto, p. 1-1. 15 out. 2020.

CARVALHO, M.P. Dicas para a construção e utilização de sombrites. São Paulo: MilkPoint, 2001. Disponível em: 〈httpp:www.milkpoint.com.br/artigos/produção/dicas-paraa-construção-eutilização-de-sombrite-16746n.aspex>. Acesso em: 15 out. 2019.

CANAL RURAL: Preço do leite acumula alta de $42 \%$ em 2020 e deve subir ainda mais. São Paulo, 17 out. 2020. 
CONCEIÇÃO, M.N. Avaliação da influência do sombreamento artificial no desenvolvimento de novilhas leiteiras em pastagens. 2008. Tese (Doutorado em Física do Ambiente Agrícola) - Escola Superior de Agricultura Luiz de Queiroz, Universidade de São Paulo, Piracicaba, 2008. doi:10.11606/T.11.2008.tde-18112008-142644.

DALCIN, V.C. Parâmetros Fisiológicos de Bovinos Leiteiros Submetidos ao Estresse Térmico. Dissertação (mestrado) - curso de Medicina Veterinária, Universidade Federal do Rio Grande do Sul-Faculdade de Agronomia, Porto Alegre-RS, Cap. 15, p.40, 2013.

FERREIRA, L.C.B. Respostas fisiológicas e comportamentais de bovinos submetidos a diferentes ofertas de sombra. Florianópolis, 2010.p. 8.

GIROLANDO. Raça girolando historia e característica. São Paulo: Milkpoint, 2019. Disponível em: https://www.milkpoint.com.br/artigos/producao-de-leite/raca-girolando-historiacaracteristicas-e-producao-224447/. Acesso em: 25 out. 2019.

HALM GL, P.A.M, GAUGLAN, J.B. Cattle respiration rate. As a function of ambiente temperature. Transactions of ASAE, v.40, p. 97-121, 1997.

HAHN, G.L.; MADER, T.L. Heat waves in relation on thermoregulation, feeding behavior, and mortality of fedlocattle. In : INTERNATIONAL LIVESTOCK 42 Environment Symposium, 5., Mennesota, 1997. Proceedings [...]. ST. Joseph: ASAE, 1997. p. 125-120.

JULIVAN. Principais vantagens das telas de sombreamento (sombrite). 2018. Disponível em: https://www.agrolona.com.br/tela-de-sombreamento-sombrite/Acesso em: 12 dez. 2019.

LALONI, L.A. Índice de previsão de produção de leite para vacas Jersey em clima tropical. Tese (Doutorado) - Curso de Engenharia Agrícola, Construções Rurais e Ambiência, Faculdade de Engenharia Agrícola da Faculdade Estadual de Campinas, Campinas-SP, 102 f, Cap. 1, 2011.

MARCELINO, R A; et al., Importância do conforto térmico para o rebanho leiteiro: Radiação solar e altas temperaturas são elementos estressantes responsáveis por baixa performance. Maringá-Paraná: Ipec, 7f, p.1, 2017. Disponível em:

<httpp://iepec.com/importância-do-conforto-termico-para-o-rebanho-leiteiro/>. Acesso em: 27 ago. 2019

MARIA, D. M. R. A; et al., Bioclimatologia aplicada à produção de bovinos leiteiros nos trópicos. Teresina-PI, 2009.

MARTELLO, L.S; et al., Respostas Fisiológicas e Produtivas de Vacas Holandesas em Lactação Submetidas a Diferentes Ambientes. R. Bras. Zootec., v.33, n.1, p.181-191, 2004.

MATARAZZO, S.V. Eficiência do sistema de resfriamento adiabático evaporativo em confinamento do tipo freestall para vacas em lactação. 2004. Tese (Doutorado em Física do Ambiente Agrícola)- Escola Superior de Agricultura Luiz de Queiroz, Universidade de São Paulo, Piracicaba, 2004. DOI10.11606/T.11.2004.tde-29042005-162015.

NÄÄS, I.A. Biometeorologia e construções rurais em ambiente tropical. In: CONGRESSO BRASILEIRO DE BIOMETEOROLGIA,2. Anais [...], Sociedade Biometeorologia, Goiana p.63-73 1998. 
PEREIRA, J.C.C. Fundamentos de Bioclimatologia Aplicados a Produção Animal. Belo Horizonte: FEPMZ-Editora, p.195, 2005.

REHAGRO. Estresse térmico em vacas leiteiras: impacto na produção animal. 2018.

Disponível em: 〈https://rehagro.com.br/blog/estresse-termico-em-vacas-leiteiras/>. Acesso em: 25 nov. 2019.

SILVA, L.A.C. Avaliação do bem estar em bezerros leiteiros com a utilização de sombrite no piquete. TCC (Graduação) - Curso de Medicina Veterinária, Faculdade Dr. Francisco Maeda - Fafram, Ituverava-SP, 2019. 36.f, Cap. 5, 2019. 